\title{
Influence of irradiation on stainless steel corrosion in PWR primary conditions
}

\author{
Stéphane PERRIN ${ }^{1}$, Marie DUMERVAL ${ }^{1}$, Loic MARCHETTI ${ }^{1}$ Mohamed SENNOUR ${ }^{2}$, \\ François JOMARD ${ }^{3}$, Sylvain VAUBAILLON ${ }^{4}$, Yves WOUTERS $^{5}$ \\ ${ }^{1}$ CEA-DEN-DPC, Service de la Corrosion et du Comportement des Matériaux dans leur Environnement, SCCME (Saclay, France) \\ ${ }^{2}$ MINES ParisTech, PSL - Research University, MAT - Centre des matériaux (Evry, France) \\ ${ }^{3} \mathrm{CNRS}$, Groupe d'Etude de la MAtière Condensée (Versailles, France) \\ ${ }^{4}$ CEA, RHF, INSTN, UEPTN (Saclay, France) \\ ${ }^{5}$ SIMaP, Université de Grenoble, (Grenoble, France)
}

Some internal components of pressurized water reactor (PWR) are made on stainless steel. They are exposed to:

- a corrosive environment which is the primary medium that is to say water at high temperature $\left(290^{\circ} \mathrm{C}-330^{\circ} \mathrm{C}\right)$ and high pressure $\left(155\right.$ bars) with boric acid $\left(\mathrm{H}_{3} \mathrm{BO}_{3}\right)$, lithium hydroxide ( $\left.\mathrm{LiOH}\right)$ and dissolved hydrogen,

- a mechanical stress,

- an irradiation process due to neutron flux which can cause up to 1 displacement per atom (dpa) by year.

In these conditions, these materials can be damaged by a process of IASCC (Irradiation Assisted Stress Corrosion Cracking). This degradation process has been observed since the eighties with the formation of cracks on baffle bolts under operating conditions. Oxide film rupture is the first step in this corrosion process and thereby the properties of the oxide formed on stainless steels are key parameters relative to SCC initiation. The morphology and the structure of the oxide formed on stainless steel in PWR primary medium have been detailed by several authors $[1,2,3]$. The oxide layer in divided in two parts: an internal and continuous layer rich in chromium and an external discontinuous layer composed of crystallites rich in iron. Moreover a nickel enrichment has been observed in the alloy under the oxide close to the alloy/oxide interface. In this alloy layer with a higher composition in nickel, a trapping of hydrogen has also been observed [4]. The aim of this work is to study the influence of defects created in the alloy by irradiation on the oxide properties (thickness, morphology, composition) and on oxygen transport in this oxide scale during exposition of stainless steel in PWR primary medium. In order to simulate the defects due to irradiation, ionic implantation have been performed. So samples of austenitic stainless steel (316L) have been implanted with Xenon ions at energy of $240 \mathrm{keV}$. Transmission Electron Microscopy (TEM) observations indicate an affected depth of about $80 \mathrm{~nm}$ with the formation of small cavities. The implanted samples have been oxidized at $325^{\circ} \mathrm{C}$ in hydrogenated primary water which simulates the primary medium in different devices, static autoclave and corrosion loop during different durations. The oxide film properties have been investigated by a set of techniques (SEM, TEM, SIMS).As shown on Fig. 1, which presents implanted sample before and after 600 hours of oxidation, it has been observed a correlation between the affected area created by implantation and the morphology of the oxide formed after corrosion test. The composition of the internal layer is also linked to the defects created by implantation.
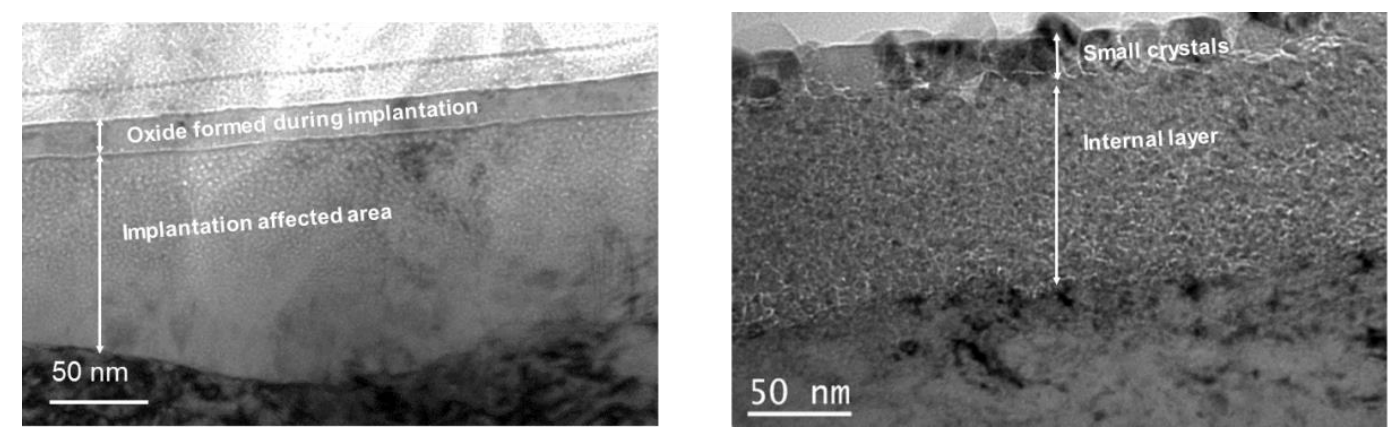

Fig. 1: TEM images on implanted 316L samples before (a) and after (b) $600 \mathrm{~h}$ of oxidation

This is an Open Access article distributed under the terms of the Creative Commons Attribution License 4.0, which permits unrestricted use, distribution, and reproduction in any medium, provided the original work is properly cited. 
Moreover the study of oxidation kinetic evaluated by ion beam analysis (NRA and RBS) have shown that the growth rate of the internal oxide layer follows a logarithmic-type law: after a $24 \mathrm{~h}$ exposure, the internal oxide reaches a thickness equivalent to the implanted affected depth which does not change much for longer exposition duration confirming the influence of the defect on the oxidation process.

Oxygen transport in the oxide layer has also been studied by two-stages corrosion experiments, a first stage in natural primary water (during 600h) followed by a second stage with water enriched in ${ }^{18} \mathrm{O}$ (during 16h). Comparison between TEM observation after implantation, EDX analysis after corrosion and SIMS analysis after these two corrosion sequences (Fig. 2) enable to link the distribution of defect created by implantation with the oxygen transport through the internal oxide layer formed during exposition in primary medium at $325^{\circ} \mathrm{C}$.

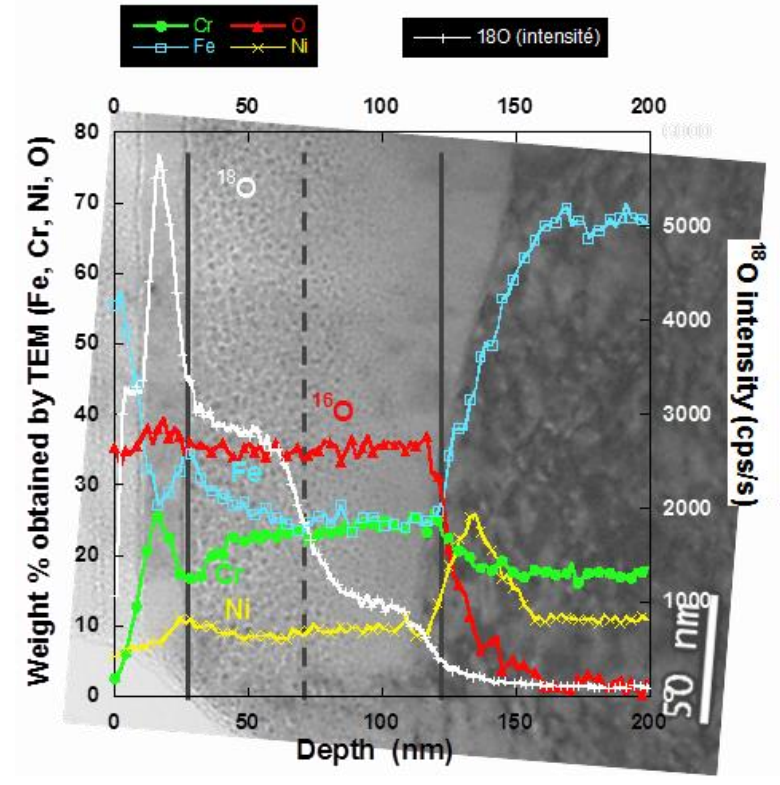

Fig 2: Superposition of TEM image showing the microstructure samples after implantation, concentration profiles of ${ }^{18} \mathrm{O}$ obtained by SIMS after two corrosion stages and $\mathrm{O}, \mathrm{Fe}, \mathrm{Cr}$ and $\mathrm{Ni}$ EDX concentration profiles obtained after $600 \mathrm{~h}$ of exposition to primary medium.

As a conclusion, this study revealed an effect of the defect distribution (generated by prior Xeimplantation) on the oxide formed on of $316 \mathrm{~L}$ in primary medium, on the oxidation kinetic and also on the oxygen transport properties in the oxide layer.

\section{References}

[1] Terachi, T. Yamada, T. Miyamoto, K. Arioka, K. Fukuyai, Corrosion Behavior of Stainless Steels in Simulated PWR Primary Water -Effect of Chromium Content in Alloys and Dissolved Hydrogen, Journal of Nuclear Science and Technology, 45 (2008) 975

[2] B. Stellwag, The mechanism of oxide film formation on austenitic stainless steels in high temperature water, Corrosion Science, 40, (1998) 337

[3] S. Perrin, L. Marchetti, C. Duhamel, M. Sennour and F. Jomard, Influence of irradiation on the oxide film formed on 316 stainless steel in PWR primary water,.Oxidation of Metals, 80 (2013) 623

[4] M. Dumerval, S. Perrin, L. Marchetti, M. Tabarant, F. Jomard, Y. Wouters, Hydrogen absorption associated with the corrosion mechanism of $316 \mathrm{~L}$ stainless steels in primary medium of Pressurized Water Reactor (PWR), Corrosion Science, 85, (2014) 251 


\section{Influence of irradiation on stainless steel corrosion in PWR primary conditions}

Marie DUMERVAL ${ }^{a}$, Stéphane PERRINa, Loïc MARCHETTIa, Mohamed SENNOUR ${ }^{b}$, François JOMARD $^{c}$, Sylvain VAUBAILLONd, Yves WOUTERS

a CEA, DEN, DPC, SCCME, Laboratoire d'Étude de la Corrosion Aqueuse, F-91191 Gif-surYvette, France.

b MINES ParisTech, PSL - Research University, MAT - Centre des matériaux, CNRS UMR 7633, BP 8791003 Evry, France

c CNRS, Groupe d'Etude de la MAtière Condensée, F-78035 Versailles, France

a CEA, RHF, INSTN, UEPTN F-91191 Gif-sur-Yvette, France

e Université de Grenoble, SIMaP, F-38402, Saint Martin d'Hères, France

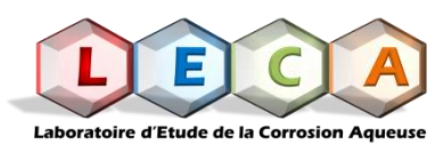




\section{CEA CONTEXT}

\section{MIN口S}

Severe irradiation conditions

in PWR core (RPV+internals)

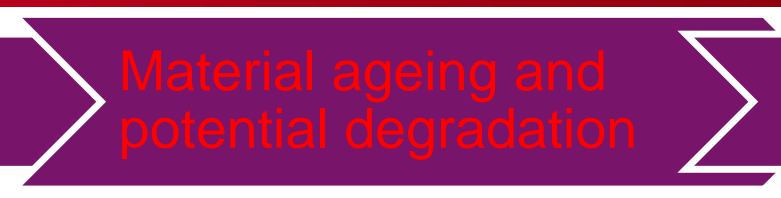

Limit of reactor operational life
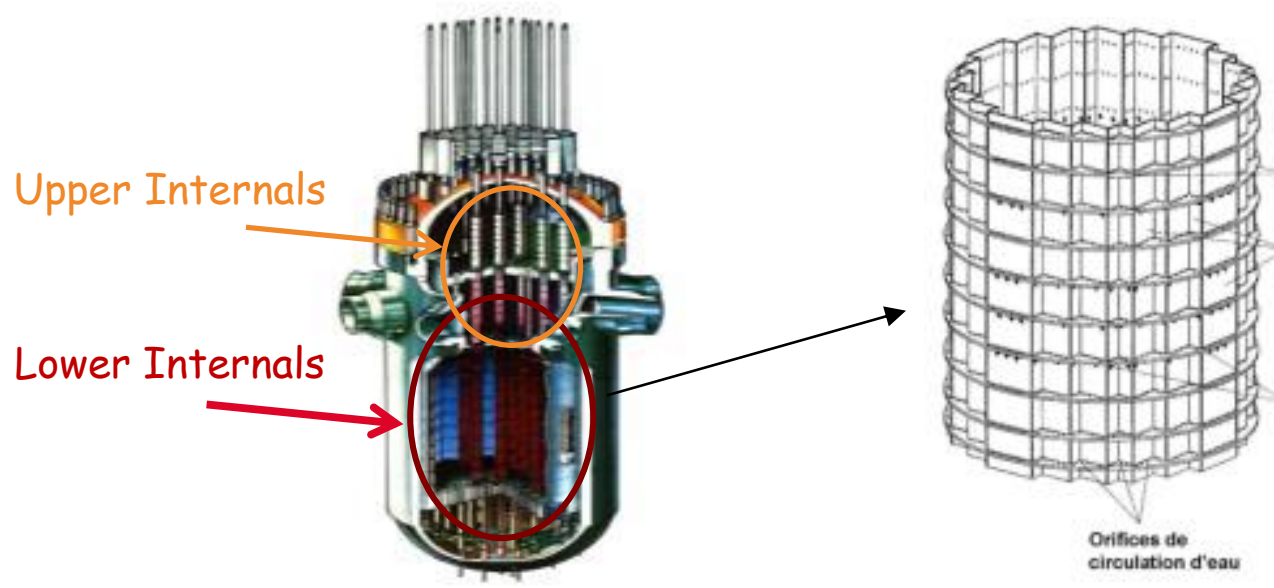

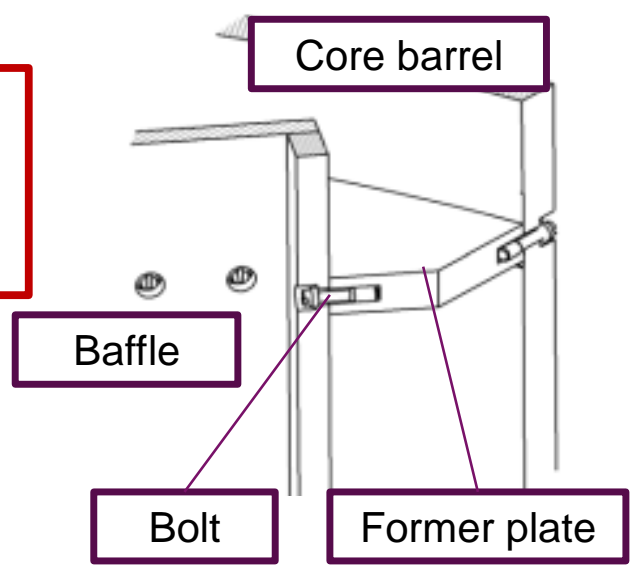

IASCC of the baffle/former bolts
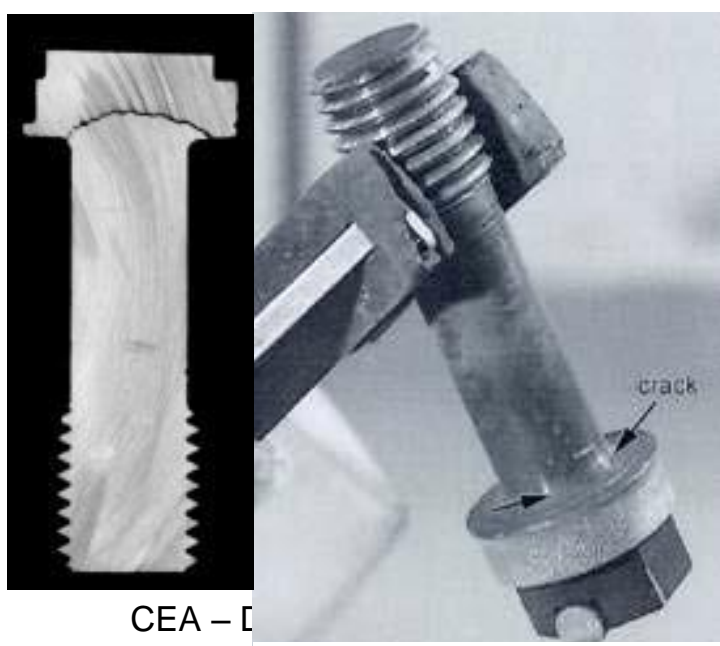

$\rightarrow I G$ Crack at the head to shank transition region $\left(8.5 \mathrm{dpa}-300^{\circ} \mathrm{C}\right)$

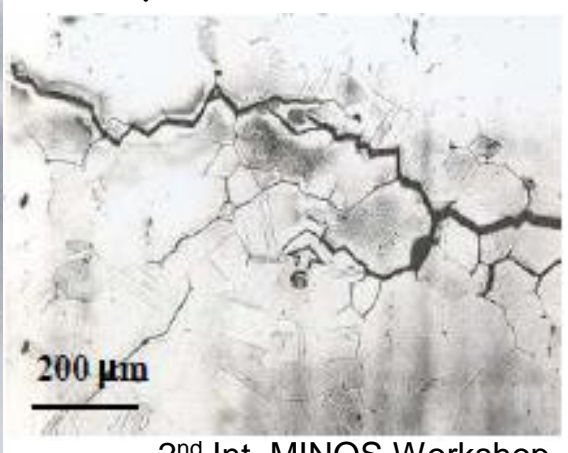

\section{IASCC initiation for PWR's bolts}

[Thomas, Fontevraud 2002] 


\section{IASCC STUDY AT CEA}

\section{$\because$ MINDS}

Strain and stress evaluations in the alloys in function of irradiation (DMN/SEMI)
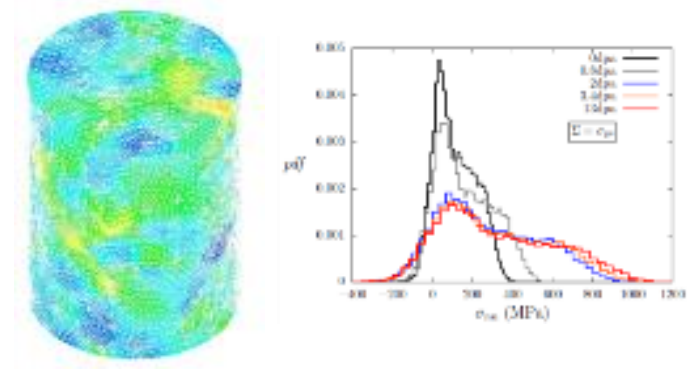

Modelling of initiation and propagation of cracks by finite element method (DMN/SRMA)

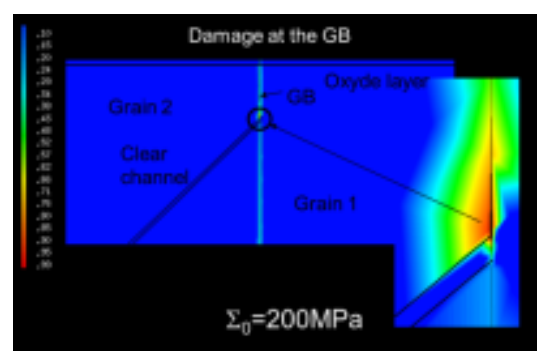

CEA - DEN
Oxidation modelling: Ekinox (DPC/SCCME)
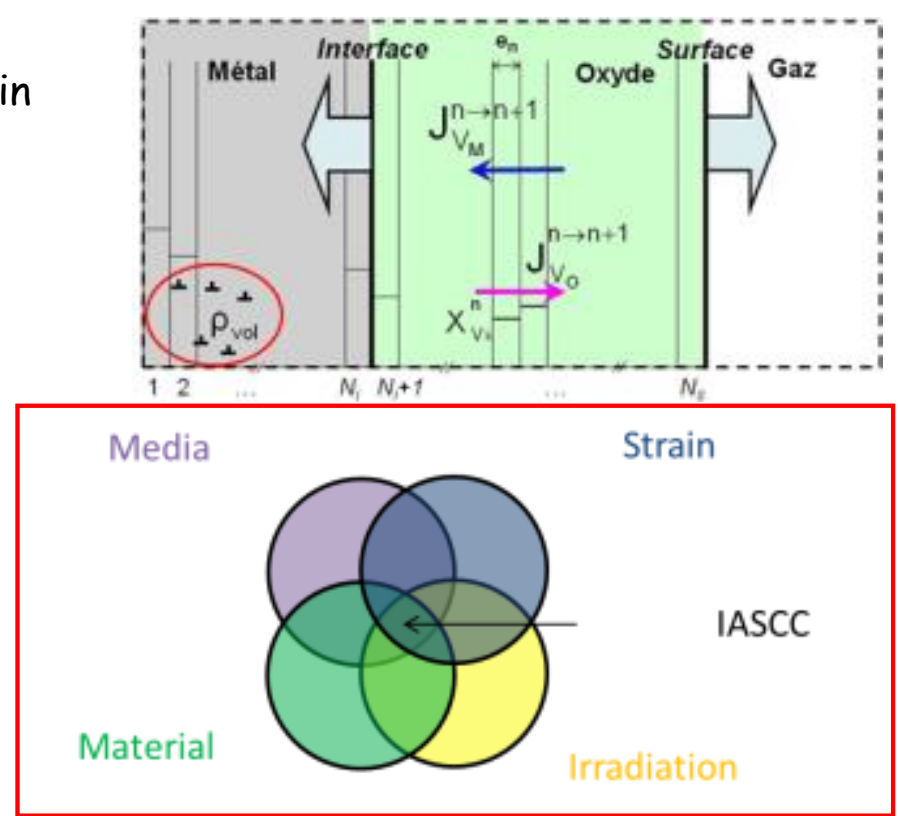

IASCC TeST (DMN/SEMI)
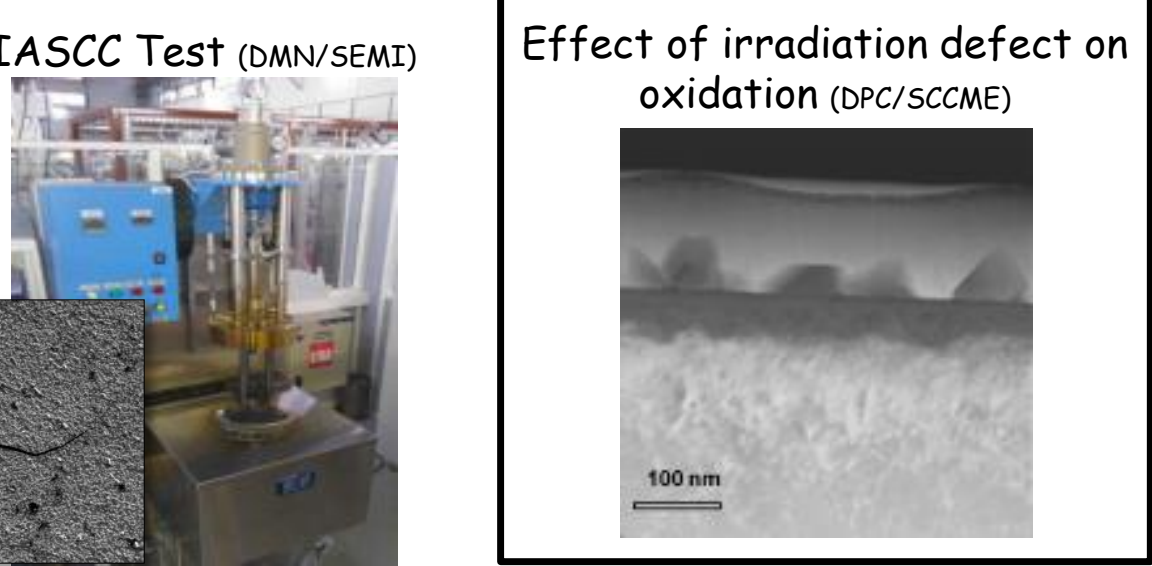

$2^{\text {nd }}$ Int. MINOS Workshop - November 4-6, 2015, CEA - INSTN Cadarache, France
Mechanical properties of oxides (MD) (DPC/SCCME)

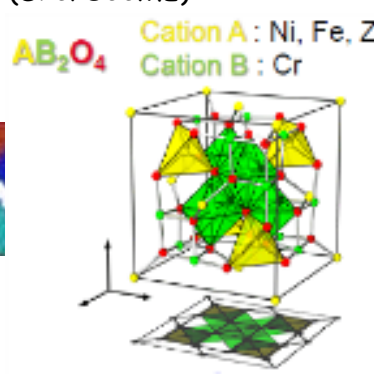

Effect of radiolysis (DPC/SCCME)

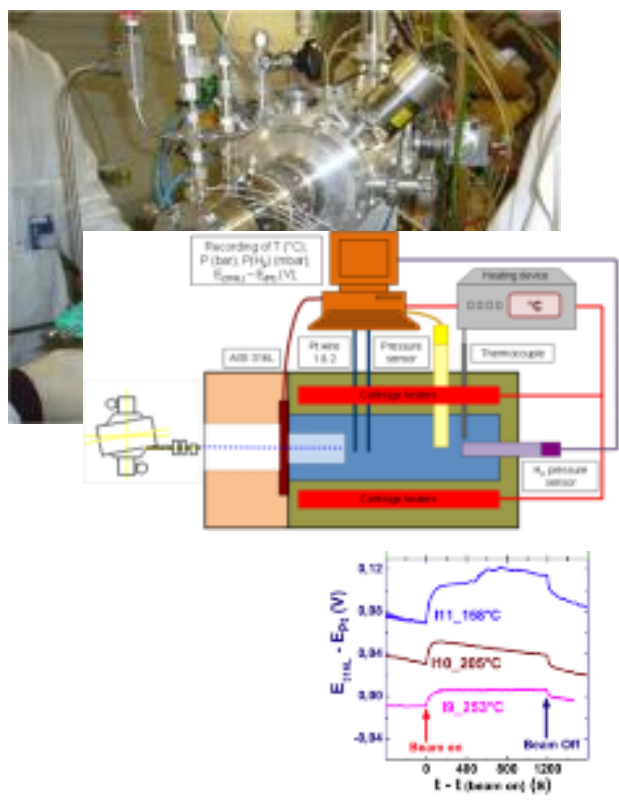




\section{Cea AIM}

\section{MINDS}

Irradiation Assisted Stress Corrosion Cracking (IASCC)
$\Longrightarrow$ First step: oxide film rupture

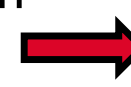

Understand the role of defects on oxidation process

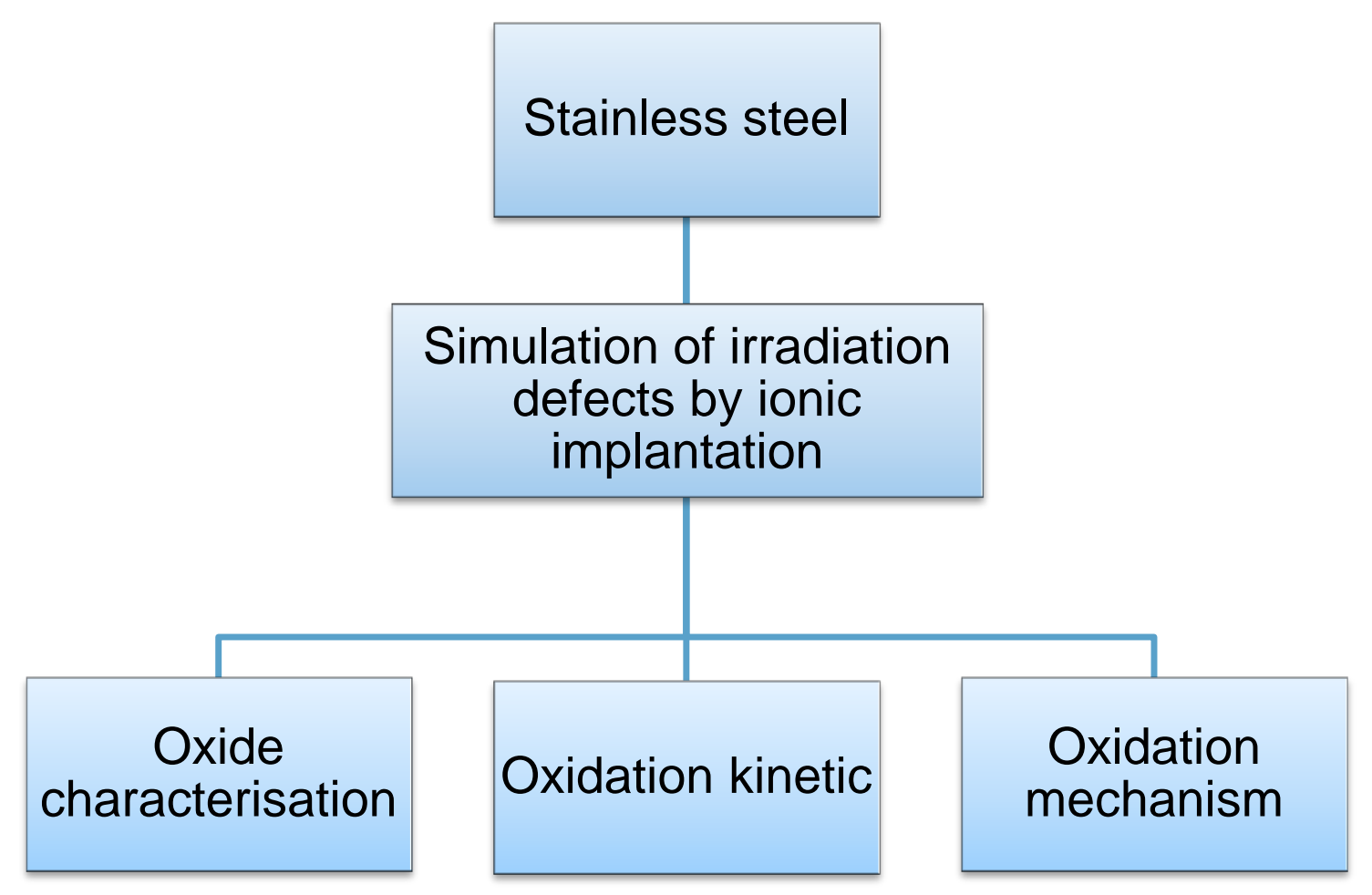




\section{Cea OUTLINE}

\section{MINDS}

$>$ Materials and methods

$>$ Oxide layer characterization on non implanted sample

> Oxide layer characterization on implanted sample

Oxide layer properties

Oxidation kinetic

Oxygen transport 


\section{MATERIALS AND METHODS}

\section{MINDS}

\section{Chemical composition}

Austenitic stainless steel 316L (composition in wt. \%)

\begin{tabular}{|c|c|c|c|c|c|c|c|c|c|c|c|}
\hline $\mathbf{F e}$ & $\mathbf{C r}$ & $\mathbf{N i}$ & $\mathbf{M o}$ & $\mathbf{M n}$ & $\mathrm{Cu}$ & $\mathbf{S i}$ & $\mathbf{C o}$ & $\mathbf{N}$ & $\mathbf{P}$ & $\mathbf{C}$ & $\mathbf{S}$ \\
\hline 68.18 & 16.6 & 10.2 & 2.21 & 1.82 & 0.43 & 0.3 & 0.11 & 0.056 & 0.033 & 0.03 & 0.028 \\
\hline
\end{tabular}

Samples preparation

> Samples mechanically polished up to $0.04 \mu \mathrm{m}$ colloidal silica suspension

$\Rightarrow$ Mirror finish and low surface roughness $\left(R_{a}=13 \mathrm{~nm}\right)$

$>$ Implanted with Xenon at $240 \mathrm{keV}\left(2.10^{16}\right.$ at. $\mathrm{cm}^{-2}$,

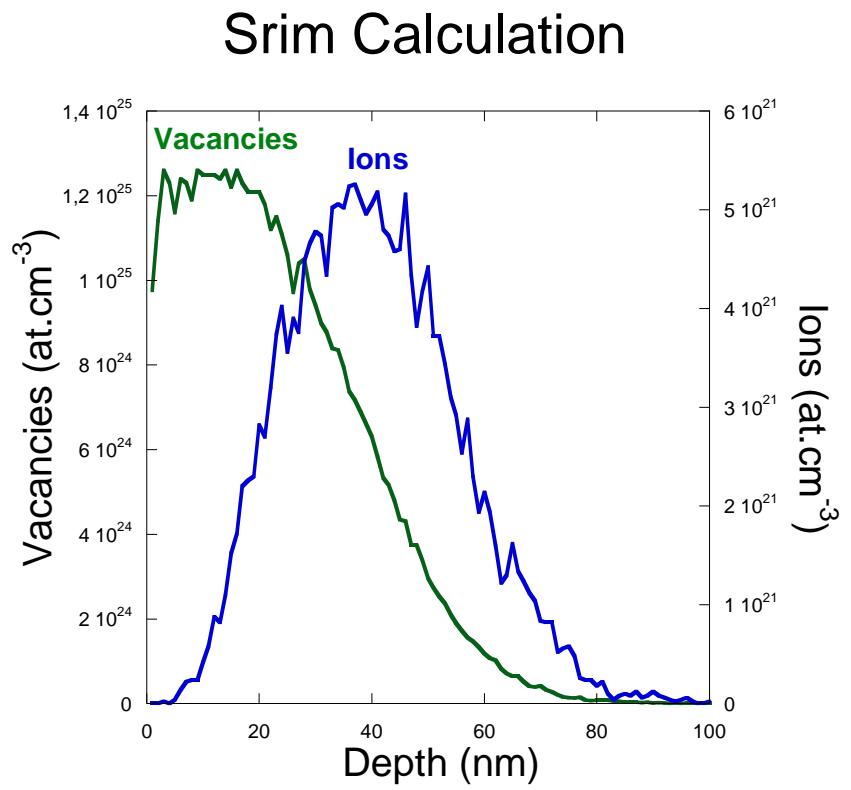




\section{MATERIALS AND METHODS}

\section{MIN口S}

\section{Samples characterization after implantation}

TEM observation after Xe-implantation

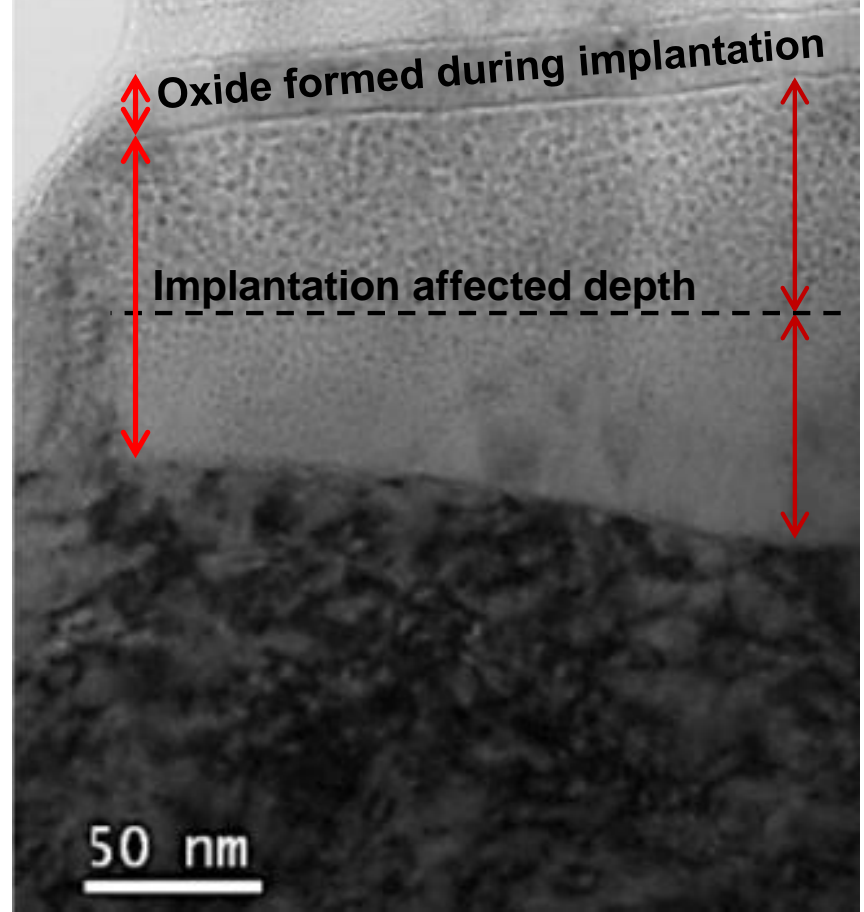

Comparison Xe profile between SRIM calculation and EDX analysis

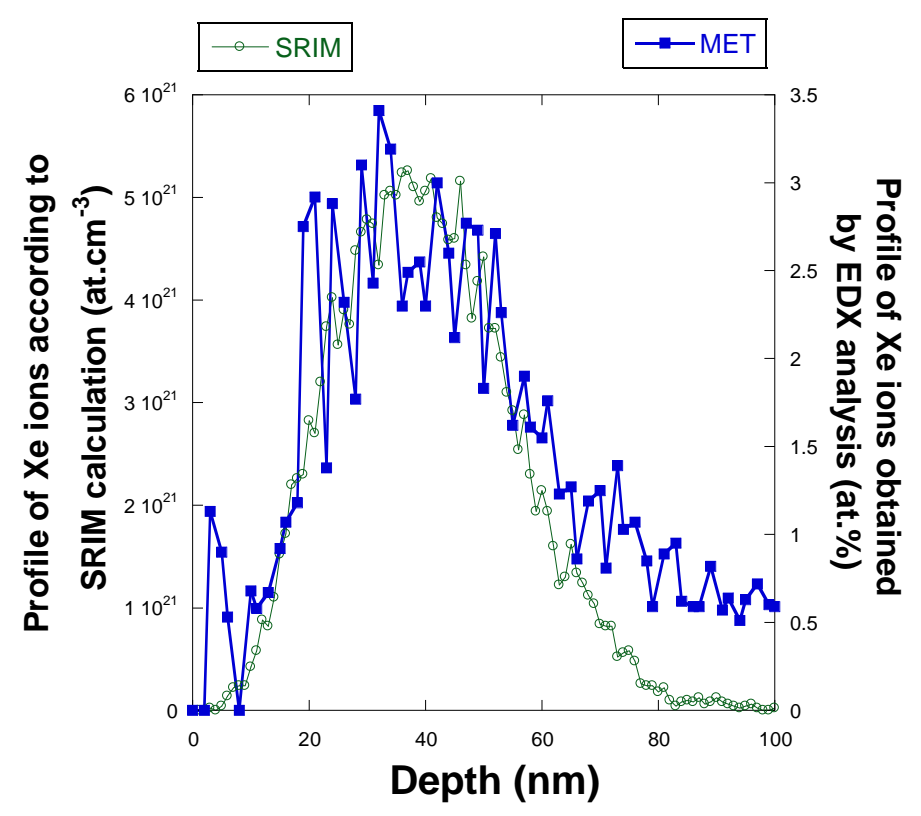

$\Rightarrow$ Formation of an affected area of about $90 \mathrm{~nm}$ divided in two parts : an upper part with higher defect density and a lower part with lower defects density 


\section{MATERIALS AND METHODS}

\section{MINDS}

\section{Samples characterization after implantation}

TEM underfocused observation

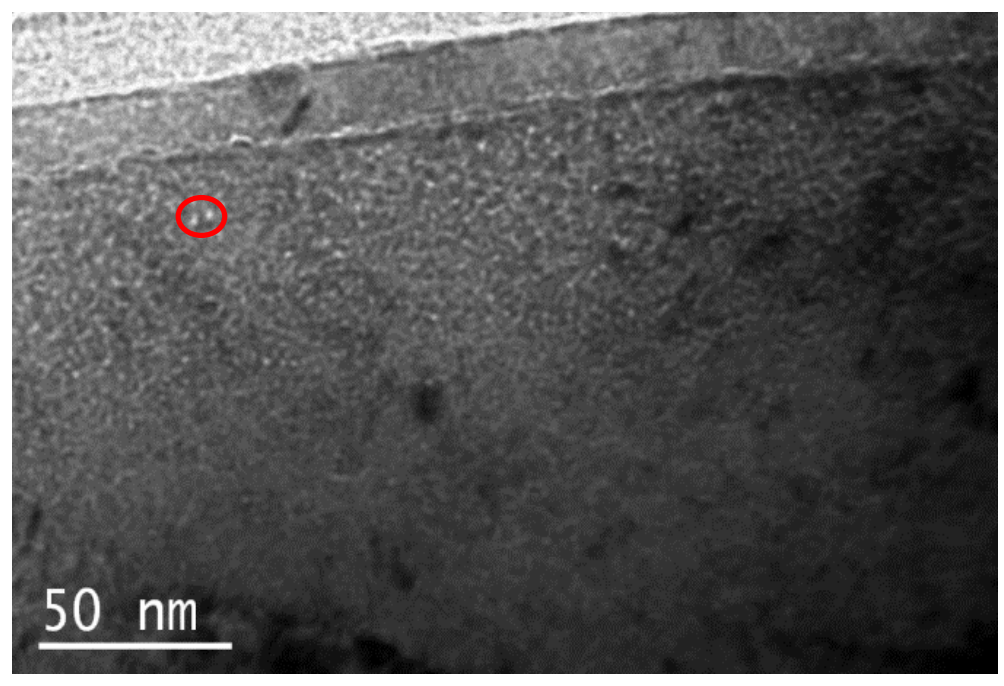

TEM overfocused observation

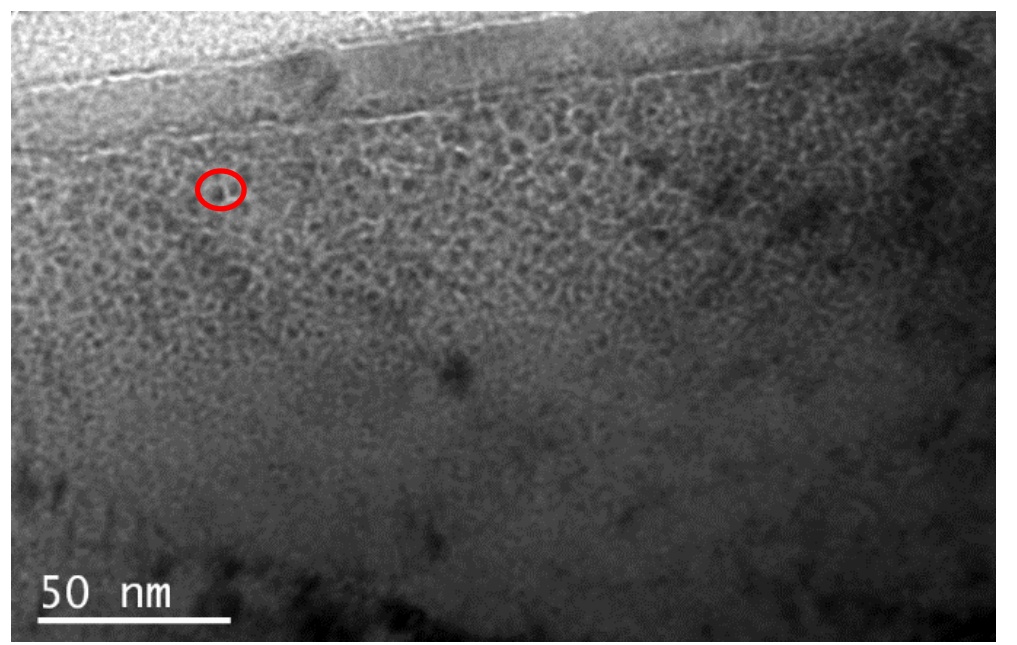

$\Rightarrow$ Defects created by irradiation $\rightarrow$ small cavities 


\section{MATERIALS AND METHODS}

\section{MINDS}

Experimental conditions:

Primary medium:

$>$ Corrosion loop

$>$ Temperature $=325^{\circ} \mathrm{C}$

$>$ Total pressure $=155$ bar

$>$ Exposure time $=24$ to $600 \mathrm{~h}$

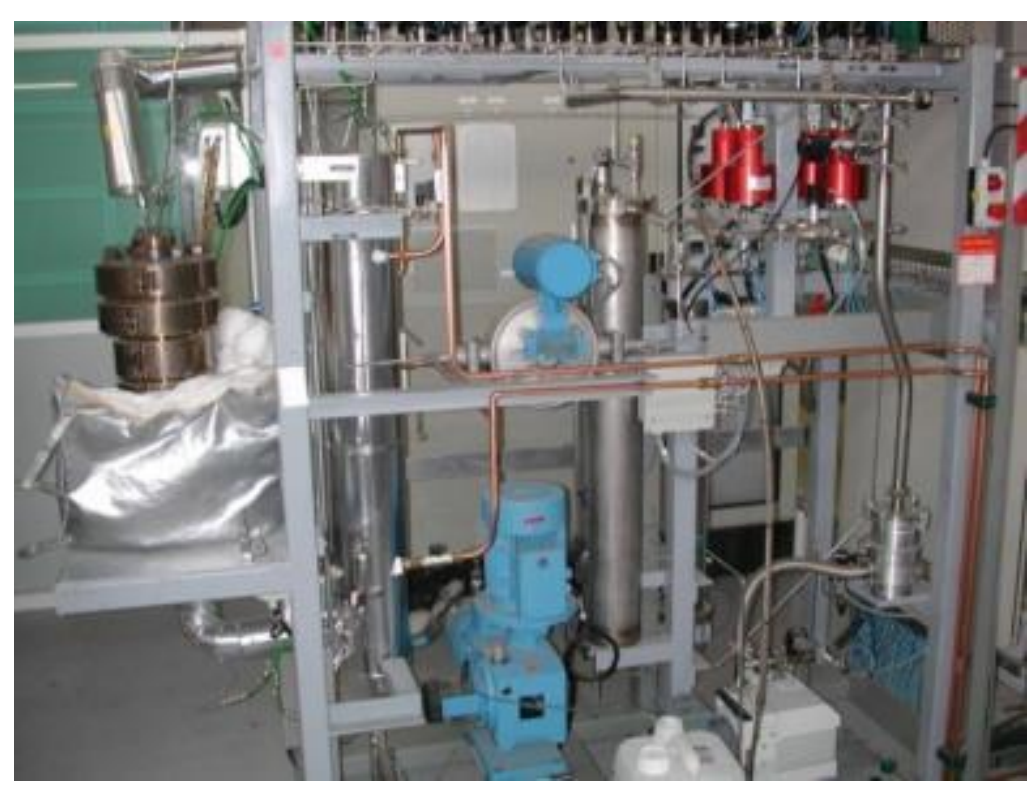

$>$ Boron $\left(\mathrm{H}_{3} \mathrm{BO}_{3}\right)=1000$ ppm

$>$ Lithium $(\mathrm{LiOH})=2 \mathrm{ppm}$

$>\mathrm{H}_{2}=0,28$ bar $\left(41 \mathrm{~cm}^{3} \cdot \mathrm{kg}^{-1}\right)$

$>\mathrm{O}_{2}<5 \mathrm{ppb}$

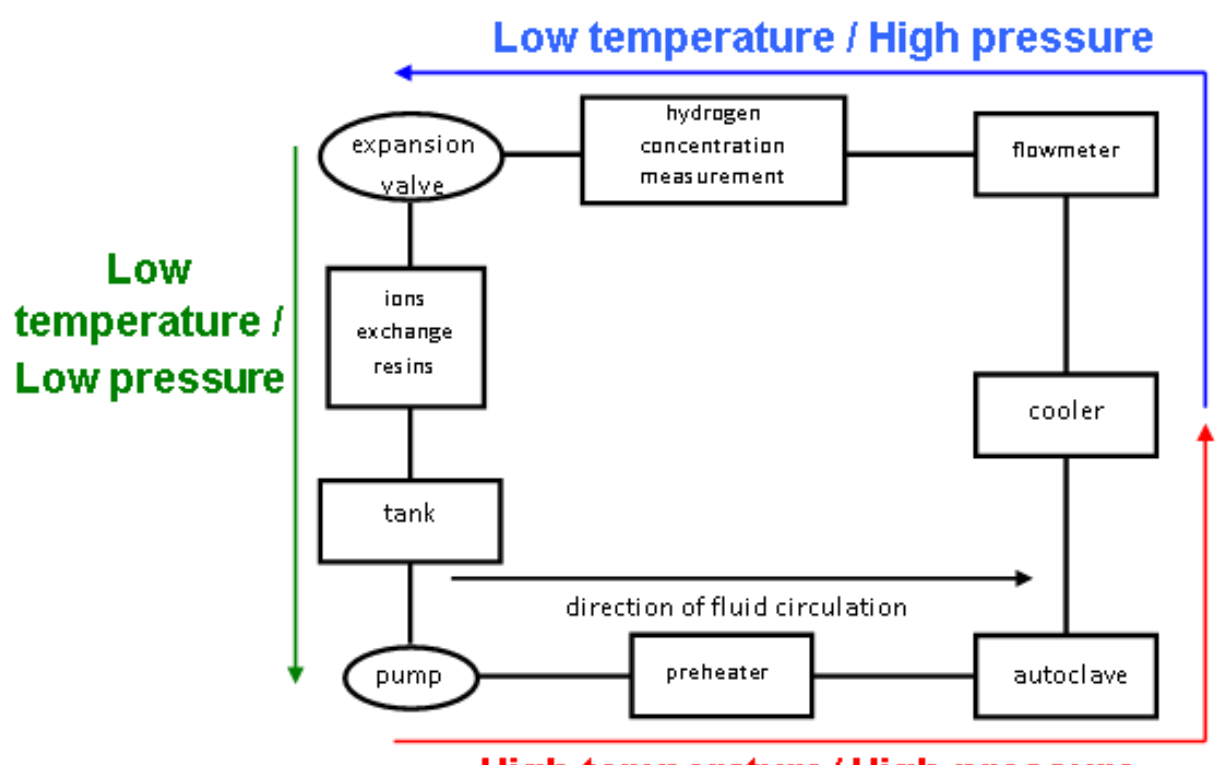

High temperature / High pressure 


\section{MATERIALS AND METHODS}

MINDS

Oxide characterization

- TEM and SEM : morphology, thickness, composition and structure of the oxide layer

- Ion beam analysis (NRA and RBS): oxide thickness in function of time (oxidation kinetics)

- SIMS analysis after two corrosion sequences using tracer : $600 \mathrm{~h}\left(\mathrm{H}_{2} \mathrm{O}\right)+16 \mathrm{~h}\left(\mathrm{H}_{2}{ }^{18} \mathrm{O}\right)$ : diffusion mechanism in the oxide layer

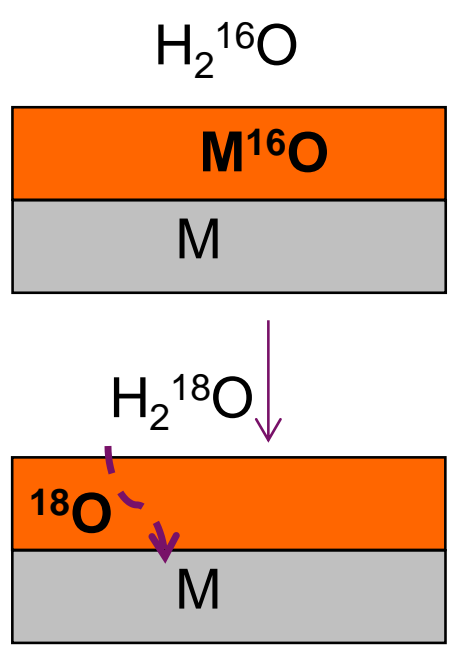




\section{MIN口S}

\section{Oxide layer formed on stainless steel in PWR primary} medium

SS $316 \mathrm{~L}$ oxidized $600 \mathrm{~h}$ in primary medium
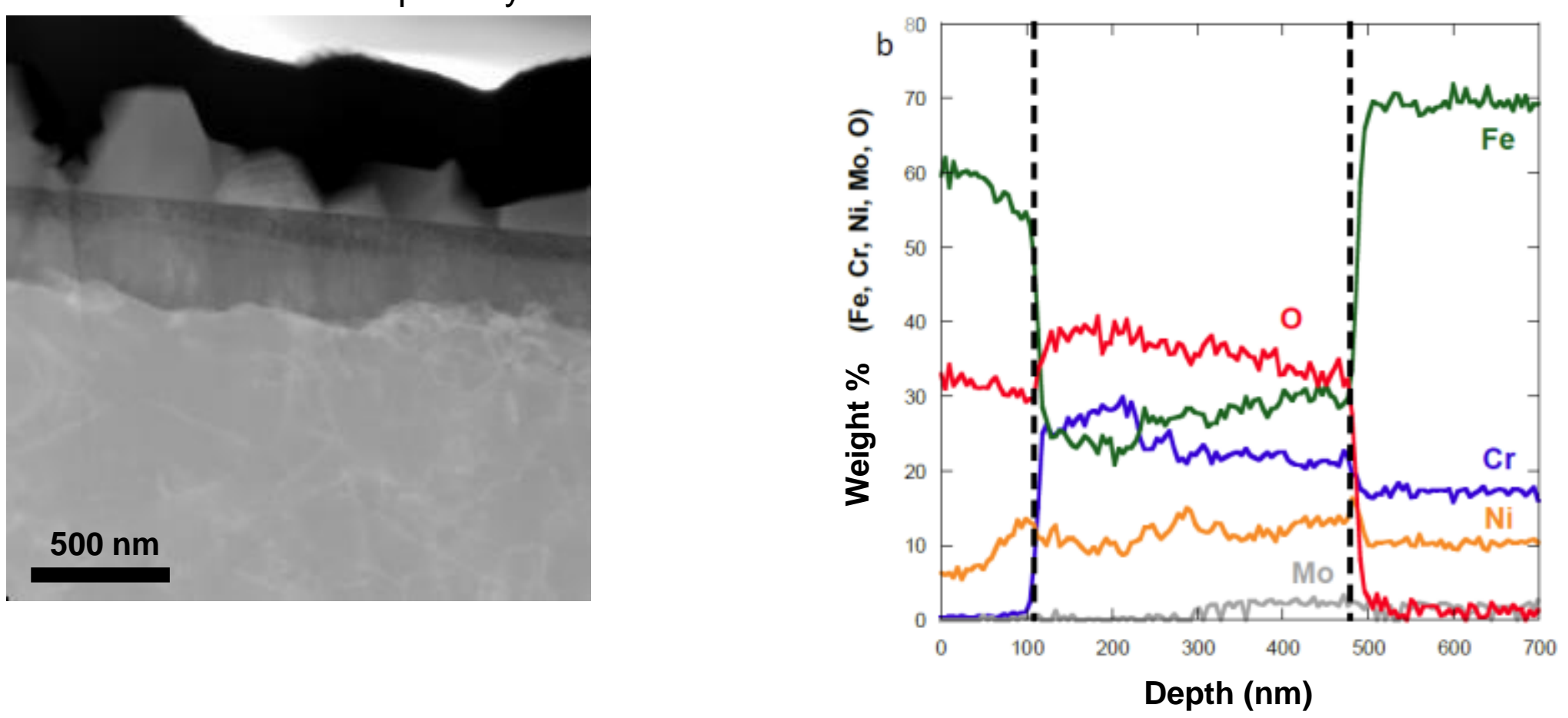


\section{Cea OXIDATION OF NON IRRADIATED SAMPLE}

\section{MINDS}

\section{Oxide layer formed on stainless steel in PWR primary}

medium

Corrosion in $\mathrm{D}_{2} \mathrm{O}$ / GD-OES analysis

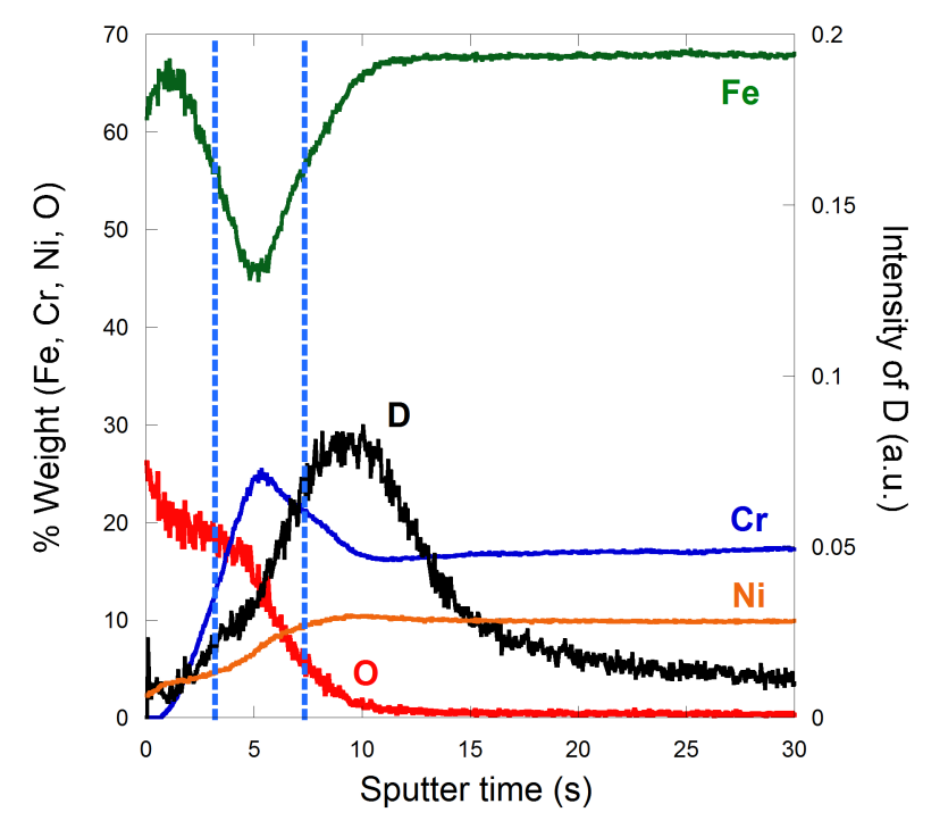

(coll. M. Tabarant (LISL)

$\Rightarrow$ Enrichment of deuterium in the alloy underlying the oxide 


\section{OXIDATION OF NON IRRADIATED SAMPLE}

\section{MINDS}

\section{Oxide layer formed on stainless steel in PWR primary}

medium

SS $316 \mathrm{~L}$ oxidized $600 \mathrm{~h}$ in primary medium

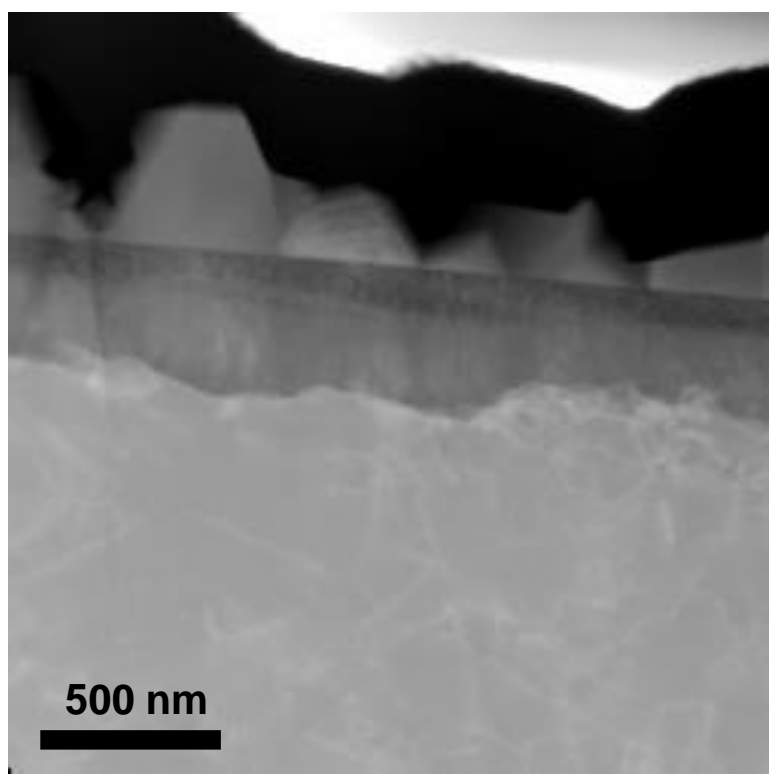

$\Rightarrow$ Well agree with other studies
Crystallites of external layer rich in Fe (spinel)

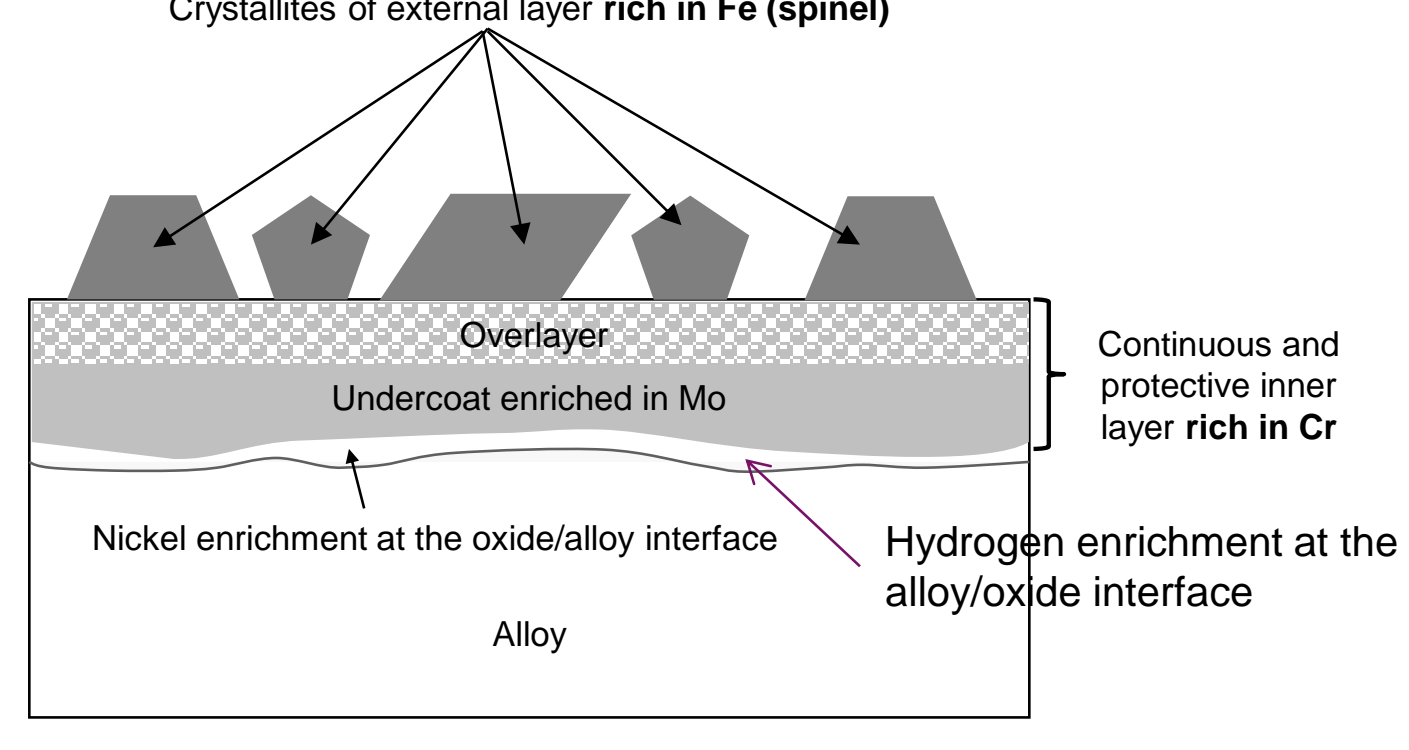

[1] T. Terachi, et al., Journal of Nuclear Science and Technology 45 (2008) 975-984.

[2] S. Lozano-Perez, et al., Acta Materialia 57 (2009) 53615381.

[3] S. Perrin, et al., Oxidation of Metals 80, (2013) 623-633 
Diffusion in the internal oxide layer

Two oxidation sequences : $600 \mathrm{~h} \mathrm{H}_{2} \mathrm{O}+16 \mathrm{~h}$ with $\mathrm{H}_{2}{ }^{18} \mathrm{O}$

SS 316 $(\mathrm{TT})$ oxidized $600 \mathrm{~h}$ in primary medium
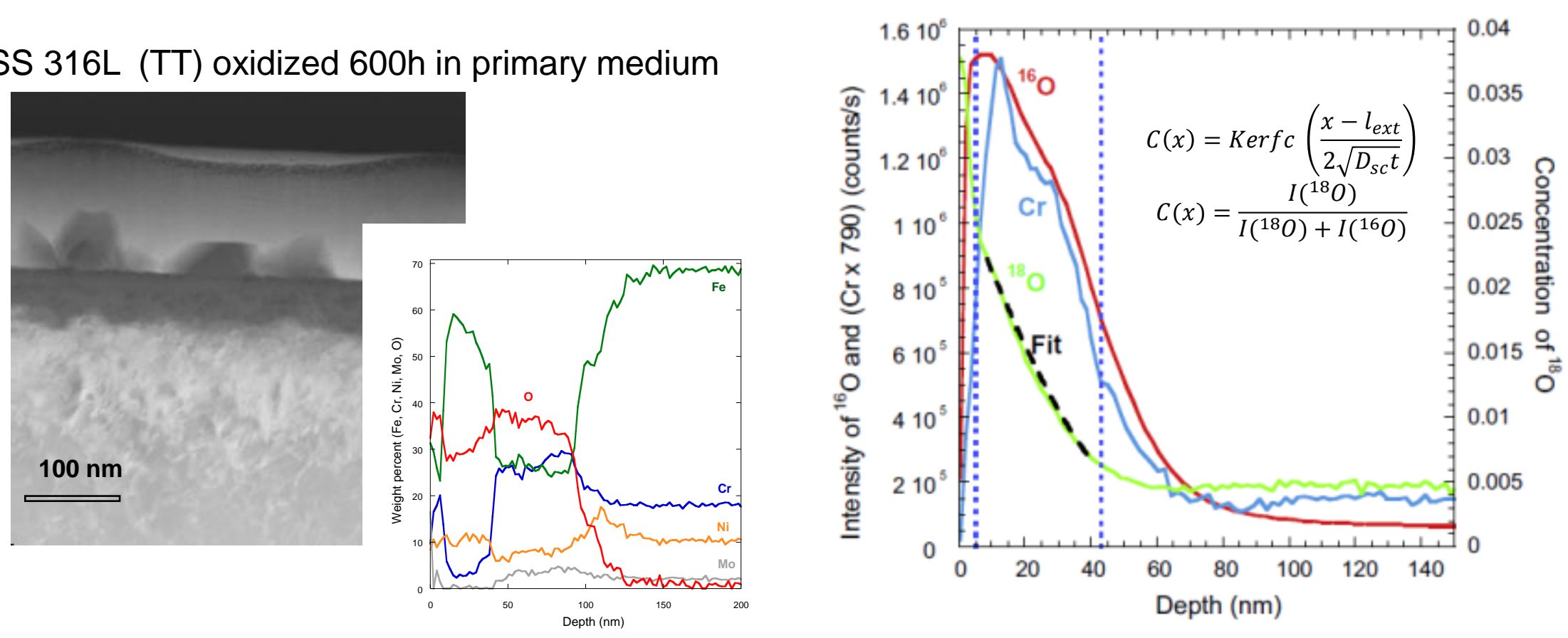

$\Rightarrow$ Diffusion profile of ${ }^{18} \mathrm{O}$ in the internal oxide layer (anionic growth)

$\Rightarrow$ Calculation of diffusion coefficient : $D_{0}=(9 \pm 1) \cdot 10^{-17} \mathrm{~cm}^{2} \cdot \mathrm{s}^{-1}$ 


\title{
OXIDATION OF NON IRRADIATED SAMPLE
}

\section{MINDS}

\author{
Diffusion in the internal oxide layer
}

Comparison with others values of $\mathrm{O}$ diffusion coefficient

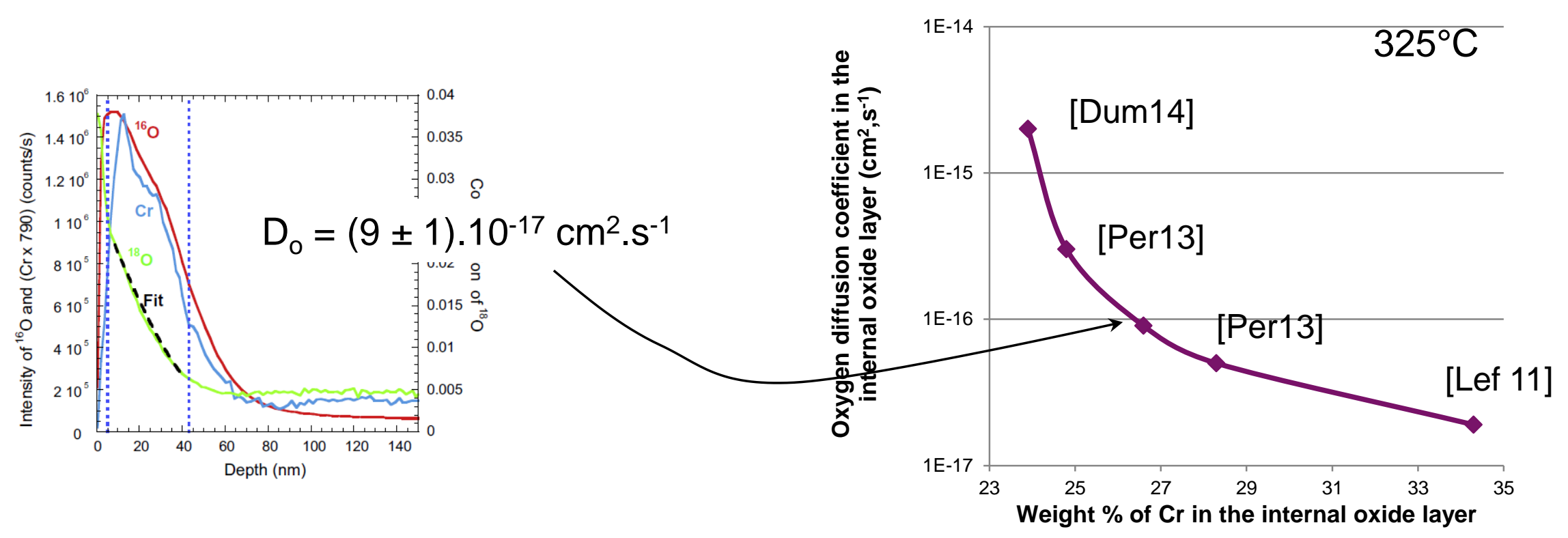

$\Rightarrow$ Link between chromium content in the oxide layer and the diffusion coefficient of oxygen 


\section{OXIDATION OF IMPLANTED SAMPLE}

\section{MINDS}

Oxide layer formed on implanted sample

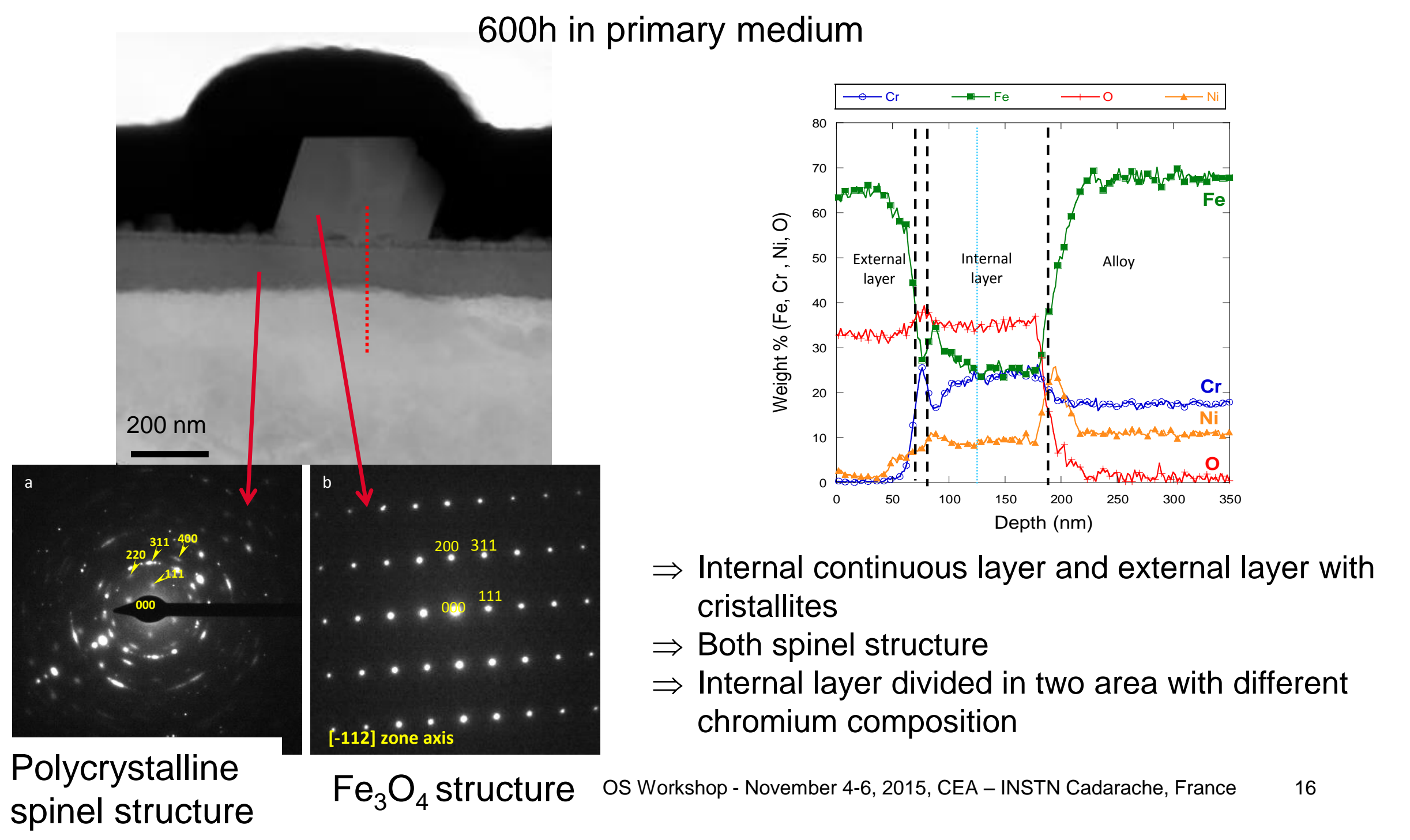




\section{OXIDATION OF IMPLANTED SAMPLE}

Evaluation of internal oxide thickness by NRA and RBS

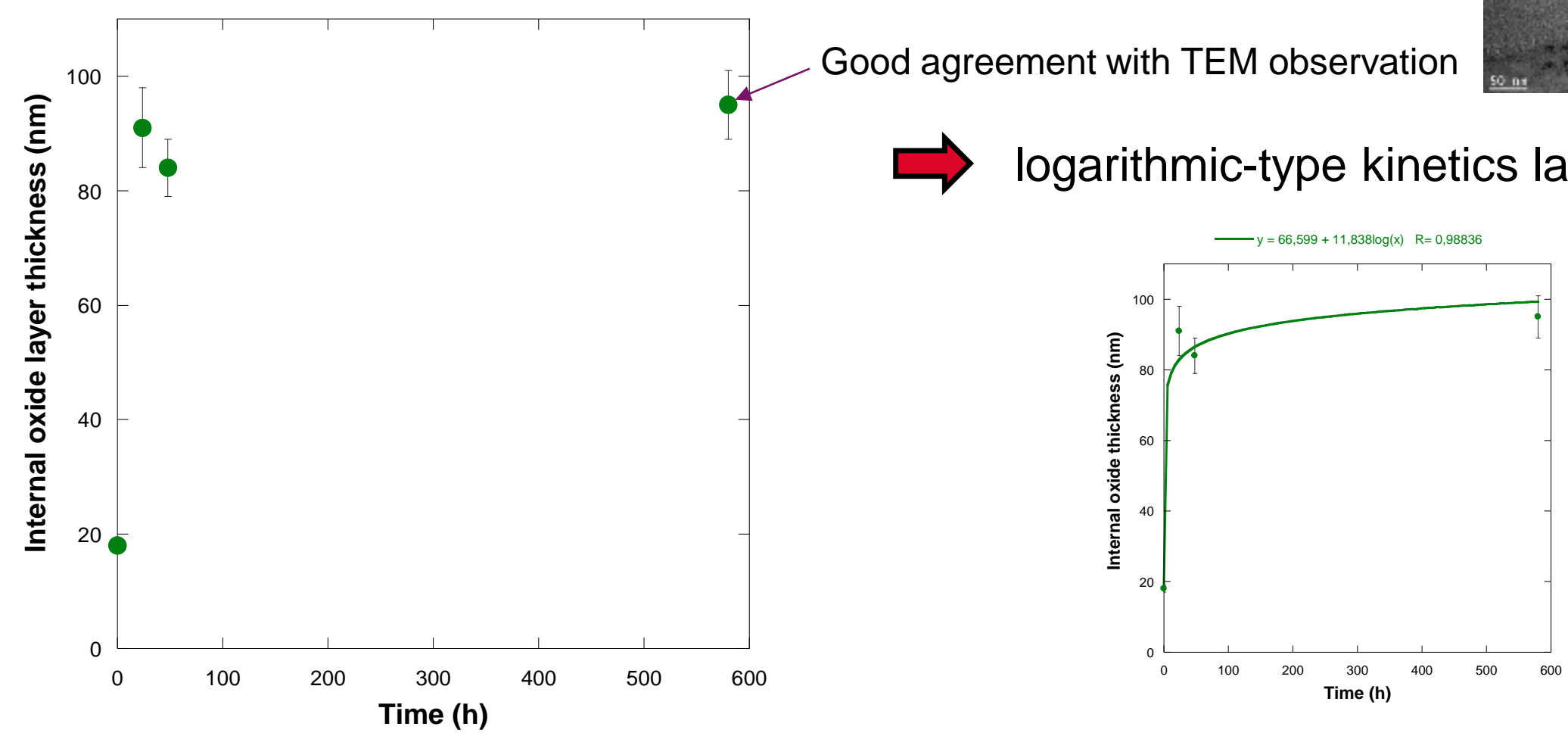

$\Rightarrow$ After $24 \mathrm{~h}$ of exposure, the thickness of the internal layer is estimated at about $90 \mathrm{~nm}$.

$\Rightarrow$ The growth rate of the internal oxide layer is fast between 0 and $24 \mathrm{~h}$ and then strongly decreases after this first period $\rightarrow$ logarithmic-type kinetics law 
Diffusion in the internal oxide layer

Two oxidation sequences : $600 \mathrm{~h} \mathrm{H}_{2} \mathrm{O}+16 \mathrm{~h}$ with $\mathrm{H}_{2}{ }^{18} \mathrm{O}$

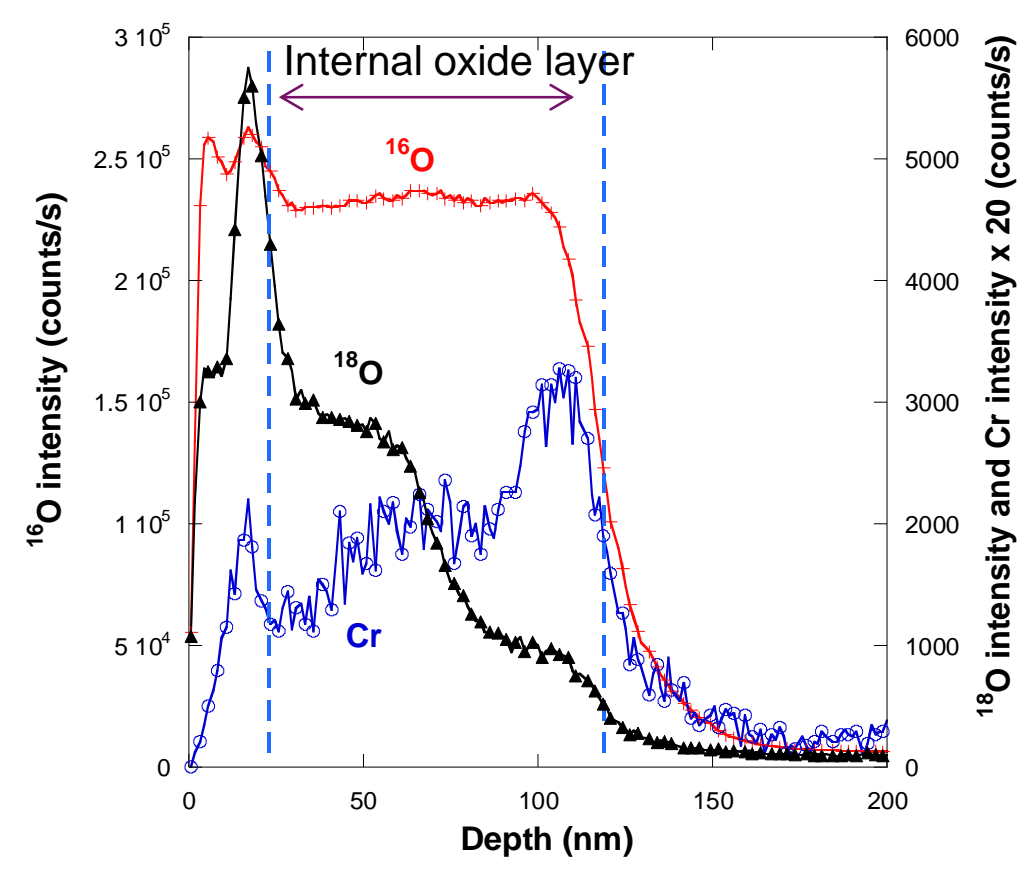

$\Rightarrow{ }^{18} \mathrm{O}$ diffusion regime does not correspond to a single diffusion profile

$\Rightarrow$ Different from profile obtained on non implanted sample

$\Rightarrow$ Two different profiles seem to be present 


\section{OXIDATION OF IMPLANTED SAMPLE}

\section{MINDS}

\section{Diffusion in the internal oxide layer}

Two oxidation sequences : $600 \mathrm{~h} \mathrm{H}_{2} \mathrm{O}+16 \mathrm{~h}$ with $\mathrm{H}_{2}{ }^{18} \mathrm{O}$

Comparison between $\mathrm{O}$ diffusion profil and oxide layer composition

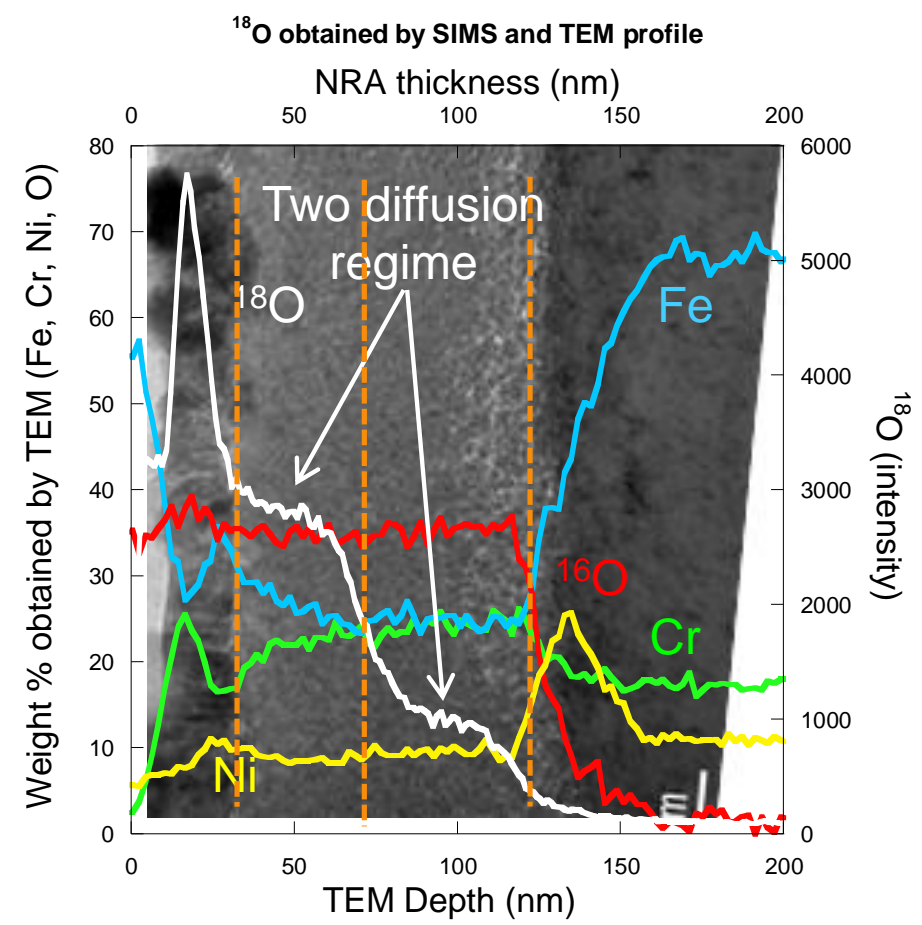

$\Rightarrow$ Link between oxygen profile in the oxide layer and its composition 


\section{OXIDATION OF IMPLANTED SAMPLE}

\section{MINDS}

\section{Diffusion in the internal oxide layer}

Two oxidation sequences : $600 \mathrm{~h} \mathrm{H}_{2} \mathrm{O}+16 \mathrm{~h}$ with $\mathrm{H}_{2}{ }^{18} \mathrm{O}$

Comparison between $\mathrm{O}$ diffusion profil, oxide layer composition and defects created in the alloy
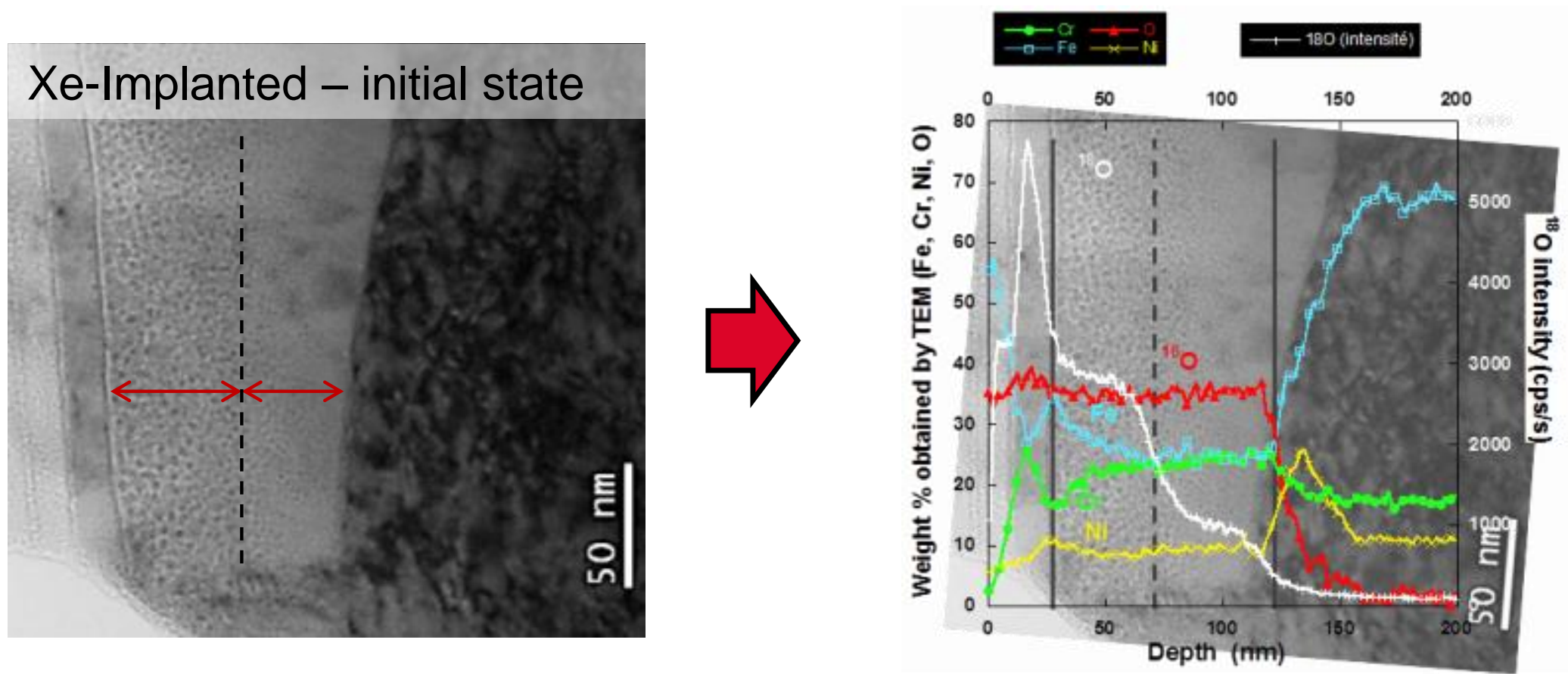

$\Rightarrow$ Link between the two diffusion regimes observed on ${ }^{18} \mathrm{O}$ profile to the initial microstructure of Xe-implanted samples 
$>$ Implantation of sample with Xe ions to create defects in the alloy

$>$ Oxidation in simulated PWR primary medium

$>$ Effect of the implanted microstructure on :

- Oxide layer thickness and composition

- Internal layer growth kinetic

- Oxygen diffusion in the oxide internal layer 